\title{
Histological Observation of Primary and Secondary Aerenchyma Formation in Adventitious Roots of Syzygium kunstleri (King) Bahadur and R.C.Gaur Grown in Hypoxic Medium
}

\author{
Hong-Duck Sou *, Masaya Masumori, Hiroyuki Kurokochi and Takeshi Tange \\ Graduate School of Agricultural and Life Sciences, The University of Tokyo, Yayoi 1-1-1, Bunkyo-ku, \\ Tokyo 113-8657, Japan; masumori@fr.a.u-tokyo.ac.jp (M.M.); h.kurokochi@gmail.com (H.K.); \\ tange@fr.a.u-tokyo.ac.jp (T.T.) \\ * Correspondence: hongducksou@hotmail.com; Tel.: +81-3-5841-5202
}

Received: 10 December 2018; Accepted: 3 February 2019; Published: 7 February 2019

\begin{abstract}
Trees growing in wetlands develop adventitious roots from the trunk during the rainy season and adapt to the flooded environment by forming primary (schizogenous or lysigenous) and secondary aerenchyma in the roots. Therefore, it is necessary to clarify the formation process of each type of aerenchyma in these adventitious roots. In this study, saplings of Syzygium kunstleri (King) Bahadur and R.C.Gaur were grown under four different treatments, and a total of 12 adventitious roots generated from trunks were used to clarify the distribution of each aerenchyma type in the roots using light or epi-florescence microscopy. Schizogenous aerenchyma was observed in the root tips where the root color was white or light brown, whereas lysigenous aerenchyma was found at some distance from the root tip where the root color gradually changed from light to dark brown. The secondary aerenchyma and periderm were observed in dark brown parts near the root base. None or only one layer of phellem cells was detected in the white roots near the root tip, but dark brown roots near the root base had at least three layers of phellem cells. Considering these results, oxygen transportation may occur between primary and secondary aerenchyma at the point where two or more layers of phellem cells are formed.
\end{abstract}

Keywords: flooding tolerance; oxygen deficiency; oxygen transport; primary aerenchyma; secondary aerenchyma; waterlogging

\section{Introduction}

Periodic or permanent flooding is a dominant environmental stress that critically impedes the growth, yield, and distribution of plants $[1,2]$. This reduction in growth and yield is caused mainly by gas diffusion being approximately 10,000-fold slower in water than in air [3,4]. Wetland plants have, therefore, adapted to hypoxic conditions through metabolic and morphological methods [5]. However, switching from aerobic respiration to the anaerobic glycolysis of ATP induces a severe reduction in energy available for maintenance, growth, and nutrient uptake [6]. Thus, in continuously hypoxic conditions, morphological and anatomical adaptation is a more efficient response for plants. Specifically, the stress caused by low $\mathrm{O}_{2}$ concentrations results in the development of aerenchyma. Aerenchyma can be found in the shoots and roots of flood-tolerant species and has been shown to improve the internal diffusion of atmospheric $\mathrm{O}_{2}$ from the aerial parts of plants to the flooded roots so as to prevent severe damage to the root system [7-11]. Thus, the development of aerenchyma is thought to be one of the most important anatomical adaptations to hypoxic conditions. 
There are two kinds of aerenchyma, namely, primary and secondary [12]. Most aerenchyma develops in the primary tissues, especially in the root cortex, and is called the 'primary aerenchyma'. The primary aerenchyma is classified based on the different ways it is formed. The first type is schizogenous aerenchyma, which forms from cells separating during tissue formation and is developmentally controlled and separate from any external stimuli [13,14]. The second type is lysigenous aerenchyma, which is formed by the death and disintegration of cells in the cortex. Here, cell death appears in a predictable pattern and is controlled by a hormone (ethylene); this is an example of programmed cell death [15]. Previous studies have shown that many important crop species, such as maize [16-18], rice [19], barley [20], and wheat [21,22], develop lysigenous aerenchyma, whereas schizogenous aerenchyma is formed in some wetland herb species such as Rumex species [23-25]. In addition, only a few species, such as Sagittaria lancifolia L., form both lysigenous and schizogenous aerenchyma, which develop in different tissues [26].

In contrast, secondary aerenchyma is a tissue of secondary origin and differentiates from the phellogen (cork cambium), cambium, or pericycle, which can produce either a porous secondary cortex or an aerenchymatous phellem in stems, hypocotyls, and roots [12,24,27-29]. In some plants, secondary aerenchyma develops radially outward from phellogen [12,30,31]; this sort of secondary aerenchyma is homologous to phellem, and thus it is referred to as aerenchymatous phellem [10,30,31]. In Lythrum salicaria L., the aerenchymatous phellem consists of alternating tissues of radially elongated cells and small isodiametric cells [12]. Past studies have shown that some flood-tolerant species such as Glycine $\max$ (L.) Merr. [27,28], Sesbania aculeata (Schreb.) Poir. [32], Se. cannabina (Retz.) Pers. [33], Se. rostrata Bremek. and Oberm. [34], Neptunia oleracea Lour. [35], and Viminaria juncea (Schrad.) Hoffmanns. [36] develop aerenchyma in the phellogen region of the stems and roots under flooded conditions. Secondary aerenchyma is anatomically different from primary aerenchyma. Although secondary aerenchyma is also thought to play an important role in supplying $\mathrm{O}_{2}$ to flooded roots $[27,37]$, information on the anatomical process by which secondary aerenchyma develops in woody plants with secondary growth is still limited [28].

Some tree species growing in wetlands develop adventitious roots from the trunk during the rainy season as an adaptation to the flooded environment [38]. Therefore, in order to understand how trees adapt to growing in such an environment, it is necessary to clarify the formation of aerenchyma in the adventitious roots, which show growth in diameter and lignification. Although there have been some reports on the induction of primary aerenchyma in a flooded environment using current-year tree seedlings $[11,28,33,39]$, few studies have been conducted using saplings.

Since only primary aerenchyma occurs at the root tip without secondary aerenchyma development [40], oxygen taken up by aboveground organs needs to be transported to the primary aerenchyma of the root tip through aerenchyma in the plant body. However, it is known that primary aerenchyma is absent near the root base [28], and oxygen to the root tip needs to be transported through secondary aerenchyma formed in the root. Several studies have been conducted on the development of secondary aerenchyma in roots [28,33,40-43]. When adventitious roots are formed, primary aerenchyma is formed anatomically at the start, and then secondary aerenchyma develops with root growth [40]. It is unknown at which stage the primary and secondary aerenchyma are connected to each other to transport oxygen. Thus, it has been hypothesized that young portions of roots may have schizogenous and lysigenous aerenchyma that connect with secondary aerenchyma at the point in the root where two or more layers of phellem cells are formed.

In this study, we aimed to examine how primary aerenchyma connects with secondary aerenchyma in adventitious roots using Syzygium kunstleri (King) Bahadur and R.C.Gaur, which is a woody plant distributed throughout Southeast Asia, especially in the peatlands of Thailand, peninsular Malaysia, and Borneo. For that purpose, we clarified how the distribution of primary and secondary aerenchyma changed in adventitious roots generated from trunks using light or epi-florescence microscopy. 


\section{Materials and Methods}

\subsection{Plant Material and Treatment}

Seeds of S. kunstleri were collected from floodplains in Narathiwat Province, Thailand, in 2011, and brought to Japan. These seeds were sown and grown for two years in a phytotron at the University of Tokyo, Japan, under a regime of $12 \mathrm{~h}$ of daylight at $30{ }^{\circ} \mathrm{C}(06: 00-18: 00), 12 \mathrm{~h}$ dark at $25{ }^{\circ} \mathrm{C}(18: 00-06: 00)$, and relative humidity of $60-80 \%$.

In 2013, two-year-old S. kunstleri seedlings were cut at $15 \mathrm{~cm}$ intervals; the diameter of each cutting ranged from 0.2 to $0.9 \mathrm{~cm}$ (average $0.6 \mathrm{~cm}$ ). The cuttings were grown in a plastic container $(60 \times 26 \mathrm{~cm}$, $27 \mathrm{~cm}$ in depth, Beramiso 60T, Daiwa, Japan) containing Akadama soil (granular loamy soil) in the same controlled-environment phytotron under well-watered conditions for five months. During the first five months, to protect the cuttings from drying, the top of the pot was wrapped with vinyl sheet. Then, the cuttings were rooted in lightproof plastic pots $(7 \mathrm{~cm}$ in diameter, $20 \mathrm{~cm}$ in height, self-made) filled with quartz sand for approximately one year.

After confirming that the cuttings began to form roots, flooding treatment was started. Treatment was performed in lightproof plastic containers $(55 \times 40 \mathrm{~cm}, 30 \mathrm{~cm}$ in depth, s-54II, Sekisui, Japan) containing the media, which were covered with styrene foam (A-XPS-B-1b, Kaneka, Japan), and wrapped with aluminum foil. In total, six containers (i.e., three containers containing hydroponic media and three containers containing agar media) were prepared. Each container included two to more rooted cuttings. Both media in the containers were hypoxic and included the following nutrients; $4 \mathrm{mM} \mathrm{NH}_{4} \mathrm{NO}_{3}, 0.6 \mathrm{mM} \mathrm{NaH}_{2} \mathrm{PO}_{4}, 0.6 \mathrm{mM} \mathrm{KCl}, 0.35 \mathrm{mM} \mathrm{CaCl}_{2}, 0.25 \mathrm{mM} \mathrm{MgSO}_{4}, 10 \mu \mathrm{M} \mathrm{FeSO}, 20 \mu \mathrm{M}$ $\mathrm{H}_{3} \mathrm{BO}_{3}, 2 \mu \mathrm{M} \mathrm{MnCl}_{2}, 2 \mu \mathrm{M} \mathrm{ZnSO}_{4}, 2 \mu \mathrm{M} \mathrm{CuSO}_{4}$, and $2 \mu \mathrm{M} \mathrm{Na}_{2} \mathrm{MoO}_{4}$ [44]. The agar medium contained $0.1 \%$ agar in order to prevent convection and thus to reduce introduction of atmospheric oxygen into the medium. Lightproof plastic plates (white) covered the surface of the media to prevent them from drying, shrinking, or being contaminated. During the experimental period, the media were refreshed every two weeks to reduce the effects of changes in composition of dissolved $\mathrm{O}_{2}$, ethylene, and $\mathrm{CO}_{2}$.

\subsection{Preparation of Samples}

We prepared four treatments (treatments A to D) as explained below.

Treatment A (n (number of adventitious roots) $=3$ ): three-month flooding with hydroponic medium.

Treatment B $(n=3)$ : three-month flooding with agar medium.

Treatment $C(n=3)$ : six-month flooding with hydroponic medium.

Treatment $\mathrm{D}(n=3)$ : six-month flooding with agar medium.

At Treatments A and C, which the same three containers containing hydroponic medium was used in, one cutting was sampled from each of the three containers after three-month flooding (Treatment A) and six-month flooding (Treatment C), respectively. One adventitious root newly extending directly from the stem was selected from each of the cuttings. Similarly, at Treatments B and D, which the same three containers containing agar medium was used in, each adventitious root was selected from the cuttings in each of the three containers after three-month flooding (Treatment B) and six-month flooding (Treatment D), respectively. The lengths over which the roots were differently colored, i.e., the white parts at the root tip, the light brown parts immediately below the root tip, and the dark brown parts near the root base, were measured using a ruler.

The selected adventitious roots were gently washed in tap water, cut into $0.5 \mathrm{~cm}$ pieces, from the tip to the root base, using a razor blade. The specimens from each root cross-section were fixed in formalin/acetic acid/alcohol (FAA) (in the ratio, formalin:acetic acid: $99.5 \%$ ethanol: $\mathrm{H}_{2} \mathrm{O}=1: 1: 9: 9$ ) and were vacuumed until the tissues had all sunk to the bottom. Dehydration was carried out by treating the desiccated specimens sequentially with $50 \%, 70 \%, 90 \%$, and $99.5 \%$ ethanol for $2 \mathrm{~h}$ at each concentration and finally with $100 \%$ ethanol for $24 \mathrm{~h}$. The specimens were then infiltrated and embedded in Technovit 7100 resin (Kulzer and Co. GmbH, Wehrheim, Germany). The polymerized 
resin blocks were glued onto wooden blocks with epoxy resin adhesive and sectioned into $7 \mu \mathrm{m}$-thick blocks using a rotary microtome (RM2235, Leica, Wetzlar, Germany).

The sections were mounted on glass slides, heated to $50{ }^{\circ} \mathrm{C}$, then stained for $3 \mathrm{~min}$ in $0.05 \%$ toluidine blue $\mathrm{O}$ and washed with water for $10 \mathrm{~min}$. To confirm the presence of phellem cells, root sections were stained for $1 \mathrm{~h}$ with a solution of fluorol yellow $088(0.01 \%$, in lactic acid) $[45,46]$. The aliphatic components of the phellem cells in cell walls can be identified by their yellow/green fluorescence under UV light. The observations of the stained sections were performed by light microscopy (BX51, Olympus, Tokyo, Japan) and fluorescence microscopy (BX51, Olympus, Tokyo, Japan; excitation filter 330-385 nm; dichroic mirror, DM $440 \mathrm{~nm}$; barrier filter, BA $420 \mathrm{~nm}$ ) and photographed with a microscope digital camera (Visualix Pro2Metrics, Visualix, Kobe, Japan).

\subsection{Observation of Aerenchyma Formation}

The distributions of primary and secondary aerenchyma were observed in all the digitized images of the root cross sections taken by the microscope digital camera. In addition, the thickness of periderm (radial length) and the number of layers of phellem cells were measured. When we counted the layers of phellem cells, if the innermost layer was partly connected with the second layer and it was difficult to separate from one another, we counted it as 0.5. Moreover, the proportions of cortex, periderm, and stele along the roots were also calculated from the root cross sections in Treatment $C$ and $D$, according to the following procedure.

The digitized images of root cross sections were subjected to cross-section analysis [47] with ImageJ software (Ver. 1.48u). ImageJ contains built-in functionality for measuring lengths and areas using area selection tools. The outlines of cortex, periderm, and stele in digitized images of root cross sections were traced with' a cursor (freehand selection tool), and their areas were quantified. The ratio of pixels to scale bar length was established during image analysis and the measurements of the selected areas were converted from pixel counts to units of $\mu \mathrm{m}$ and $\mu \mathrm{m}^{2}$.

Applying the method in the program RootScan [48], the cross section of the root was divided into cortex, periderm, and stele. Where no periderm was observed, such as near the root tip, the stele was the central part of the root; the endodermis was the outermost boundary of the stele next to the cortex. The outer boundary of the cortex was the epidermis, and root hairs were excluded. If periderm was present between the cortex and stele, range between the outermost and innermost layers of phellem was defined as periderm area.

Thus, total root cross-sectional area was defined as follows:

$$
(\text { total root cross-sectional area })=(\text { cortex area })+(\text { periderm area })+(\text { stele area }),
$$

When we measured the thickness of periderm, the layers of phellem cells, and the respective areas in each root cross-section, the measurement was done on five serial sections in each part of root and then average values were used in the following analysis. To test the difference in those values among root colors (i.e., white, light brown, and dark brown) and media, Bonferroni corrected Mann-Whitney pairwise comparison was carried out following Kruskal-Wallis test $(p<0.05)$ using SPSS Statistics Version 25 (IBM Software, New York, NY, USA). In this study, the difference among containers was not considered.

\section{Results}

\subsection{Distribution of Aerenchyma in Syzygium kunstleri Adventitious Root}

\subsubsection{Primary Aerenchyma in Cortex}

Schizogenous aerenchyma was observed in and near the root tips (Figure 1), and these roots were white and light brown. Lysigenous aerenchyma was detected throughout the roots except near the root tip in the three-month flooding treatment roots; these roots were light brown and dark brown 
(Figure 1). In the roots grown in the six-month flooding treatment, cortical cell death and degradation were observed throughout the roots. Also, cortex collapse was observed near the root base and the periderm was exposed (Figure 1).

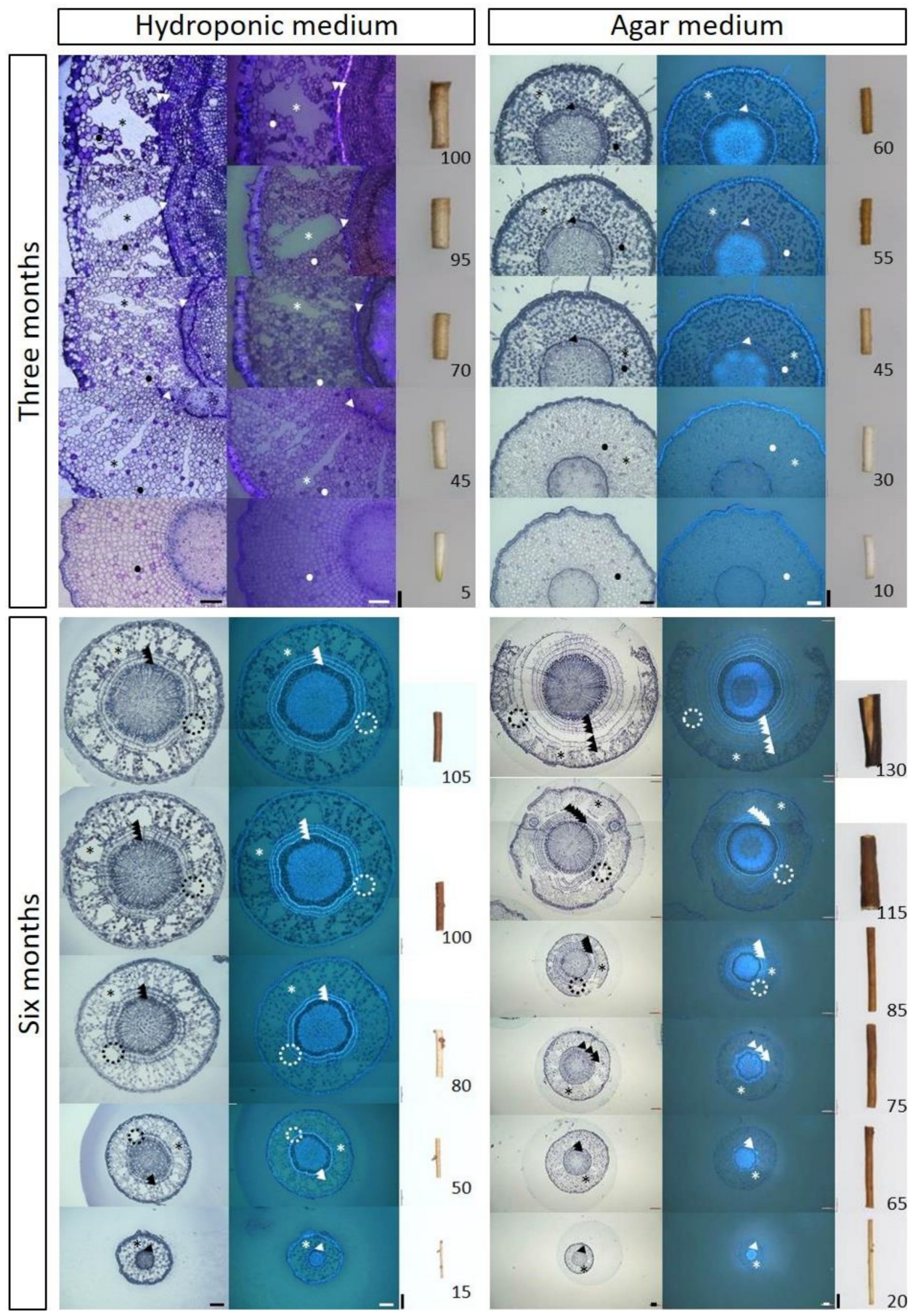

Figure 1. Serial transections of adventitious roots of Syzygium kunstleri (King) Bahadur and R.C.Gaur grown for three or six months on hydroponic and agar media. (Left) Light microphotograph; (Middle) fluorescence microphotograph; (Right) stereo microphotograph. Arrowheads (ム): layers of phellem cells; asterisks $\left(^{*}\right)$ : lysigenous aerenchyma (cortical intercellular space); dashed circle (): broken outermost layers of phellem cells, connected to primary aerenchyma (See Figure 3A,B); filled circle $(\bullet)$ : schizogenous aerenchyma. Number indicates distance behind the root tip (mm). Scale bar: left, middle $=100 \mu \mathrm{m}$; right $=2 \mathrm{~mm}$. 


\subsubsection{Development of Periderm and Secondary Aerenchyma}

Colored roots (light and dark brown) had at least one layer of phellem cells, and notably the strongly colored roots (dark brown) had at least three layers (Figure 2). Interestingly, when the roots were white, no or only one layer of phellem cells was detected (Figure 2). Dark brown parts were not observed in roots grown for three months in flooding treatments, whereas observed in root base of roots which grown for six months in flooding treatments. The root was darkest in the root base and faded in the direction of the root tip. The thickness of periderm was large in root base and small towards root tip, which was similar to the trend of color change. The number of layers of phellem cells also tended to decrease towards root tips (Figure 2). In roots grown for six months in hydroponic medium, the average thicknesses of periderm in the light and dark brown were $18.4 \mu \mathrm{m}$ and $95 \mu \mathrm{m}$, respectively. On the other hand, in roots grown for six months in agar medium, the average thicknesses in the light and dark brown were $47.4 \mu \mathrm{m}$ and $281.7 \mu \mathrm{m}$, respectively. Those values were significantly larger in roots grown for six months in agar medium. In addition, the average numbers of layers of phellem cells were 1.7 (light brown) and 3.4 (dark brown) in roots grown for six months in hydroponic medium, and 2.3 (light brown) and 5.7 (dark brown) in roots grown for six months in agar medium. Both the numbers in roots grown for six months in agar medium were also significantly larger than those in roots grown for six months in hydroponic medium. Near the root base, destruction of the outermost layer of phellem cells was observed in several root cross sections (Figure 1).

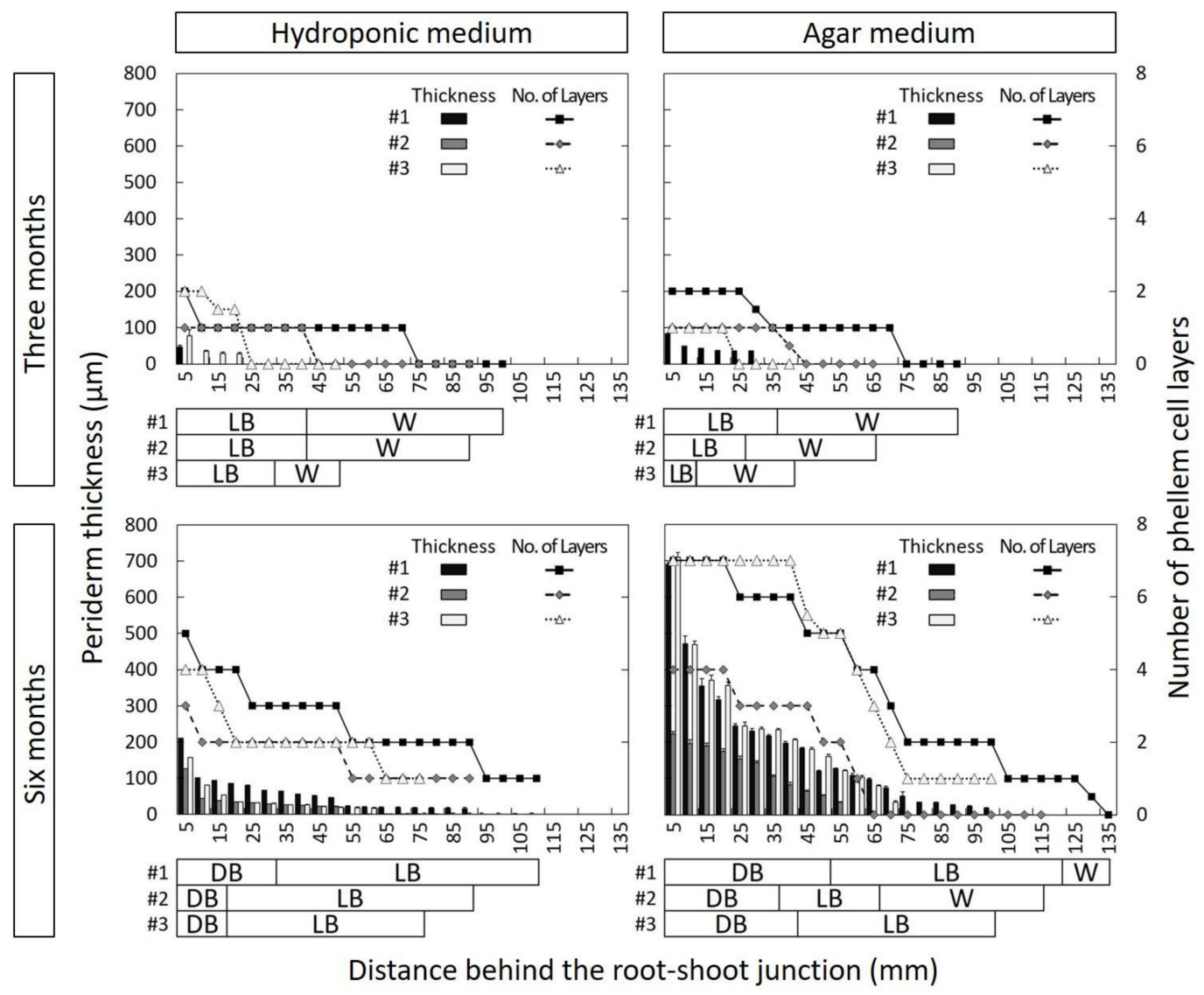

Figure 2. Distribution of periderm development along adventitious roots of Syzygium kunstleri grown for three or six months on hydroponic and agar media. Thickness of periderm (radial length) was measured and number of layers of phellem cells was counted. Bars under the graph indicate the color of root surface along the each root. Each part of roots was measured by the average of five serial sections. W: White, LB: light brown, DB: dark brown. 
The early formed layer of phellem cells detached from the next layer and the elongated cells were observed between the layers of phellem cells (Figure 3). Thus, the secondary aerenchyma was observed in the periderm (Figure 3).

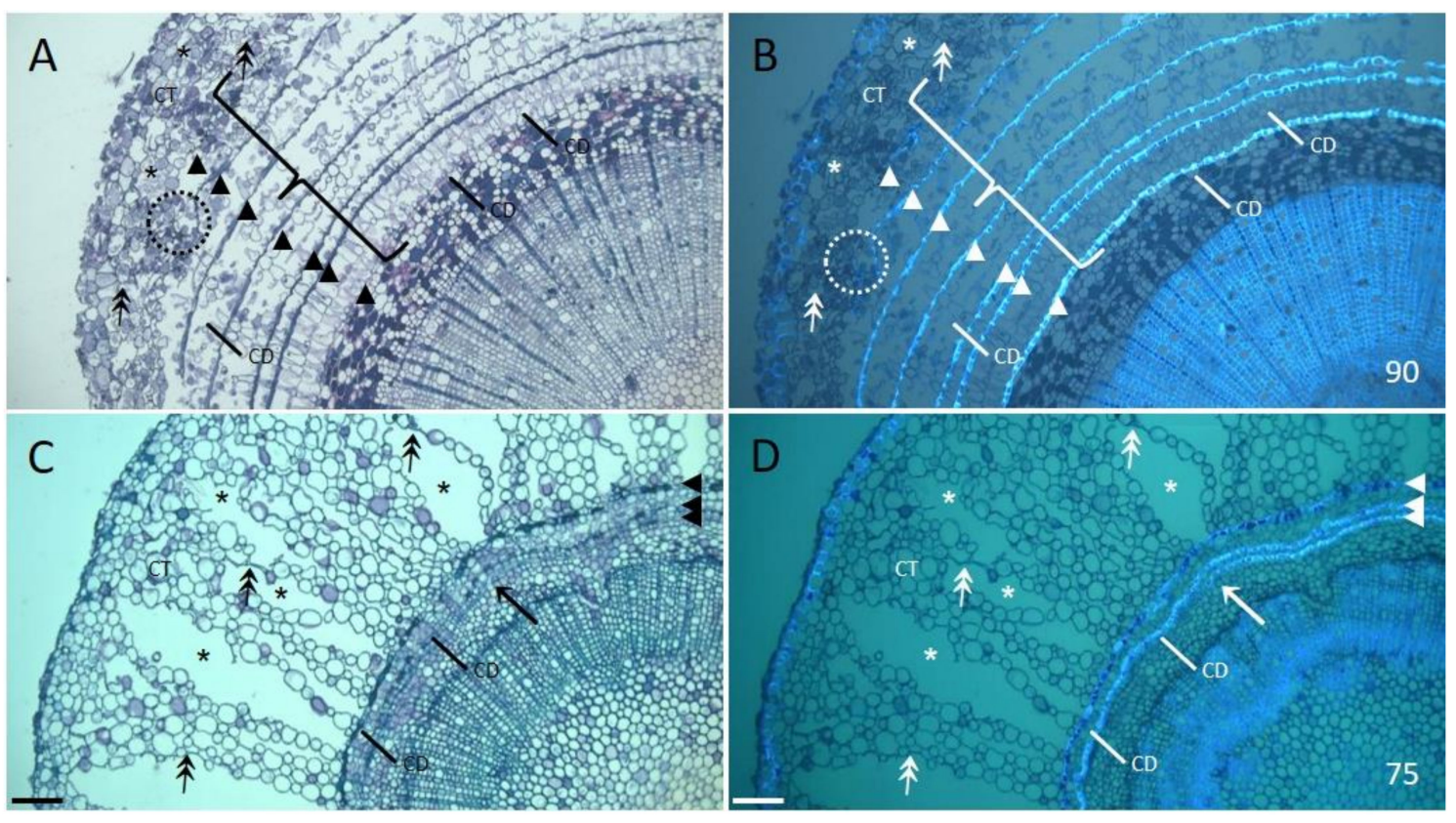

Figure 3. Transverse sections showing periderm and secondary aerenchyma formation in the adventitious roots of Syzygium kunstleri grown in agar medium for six months. (A,B) 90 millimeters behind the root tip, Figure 2 agar medium in six months \#3; (C,D) $75 \mathrm{~mm}$ behind the root tip, Figure 2 agar medium in six months \#2. (A,C) Light microphotographs; (B,D) Fluorescence microphotographs. Arrows $(\rightarrow)$ : newly formed phellem cells; arrowheads $(\mathbf{\Lambda})$ : phellem cells; asterisks $\left(^{*}\right)$ : cortical intercellular space (lysigenous aerenchyma); bracket $(\{)$ : periderm with intercellular space (secondary aerenchyma); dashed circle (): broken outermost layers of phellem cells, connected to primary aerenchyma; two headed arrows (): cortical cell degradation and death. CD: cell division occurs; CT: cortex. Scale bar $=100 \mu \mathrm{m}$.

\subsection{Proportion of Cortex, Periderm, and Stele in Each Adventitious Root Cross Section}

By the observation, we came to conceive that the thickening of periderm under the experimental conditions is made by elongation of some cells resulting in intercellular spaces. Then we thought that the area of periderm could be used as a parameter available for the comparison of aerenchymas. Since primary and secondary aerenchyma are developed in the cortex and periderm, respectively $[12,13,24,30,31]$, the proportion of cortex and periderm implies the development of primary and secondary aerenchyma, respectively. Thus, the proportions of cortex, periderm, and stele along the roots were also calculated from the root cross sections in roots grown for six months in flooding treatments (Figure 4). Cortex area comprised more than $48 \%$ of the white and light brown parts of the roots grown for six months in hydroponic and agar medium (Figure 4). The highest proportion of the periderm area was about $22 \%$ and $15 \%$ in the dark brown parts of the roots grown for six months in agar medium and hydroponic medium, respectively (Figure 4). 


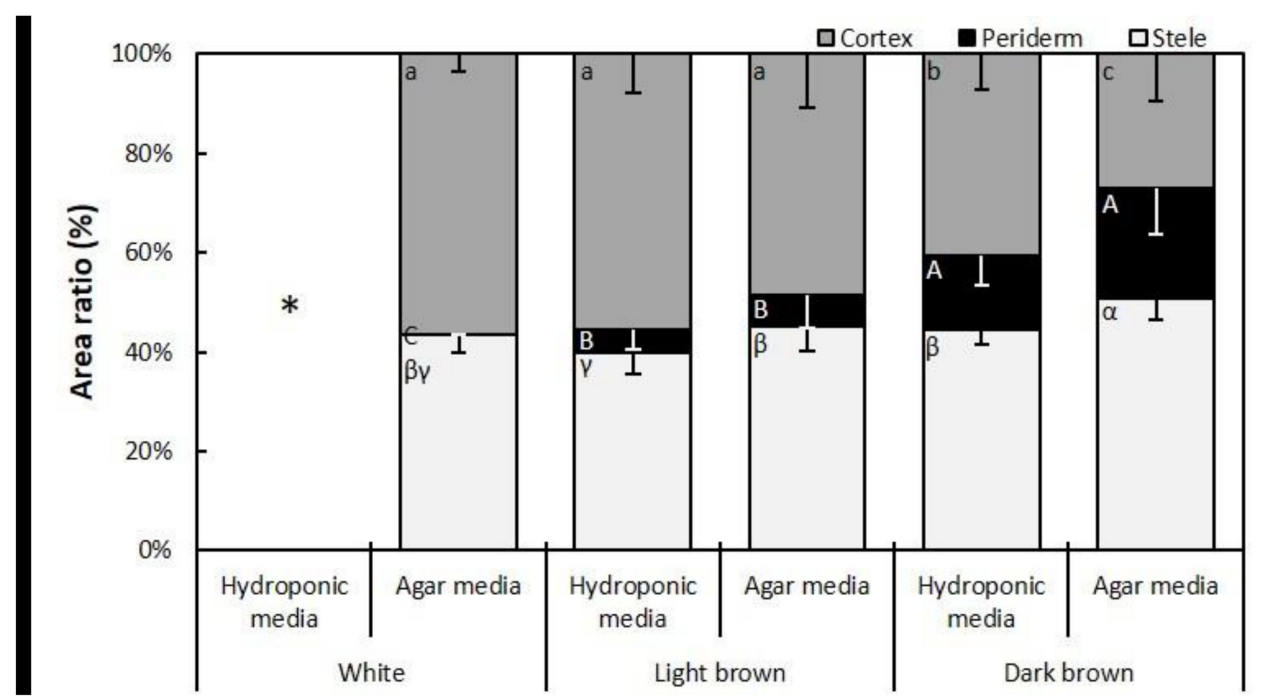

Figure 4. Changes in the proportions of cortex, periderm, and stele for different root colors of Syzygium kunstleri grown for six months in hydroponic $(n=3)$ and agar media $(n=3)$. Root cross-sectional area $=($ cortex area $)+($ periderm area $)+($ stele area $)$. Error bar; standard deviation, White, Light brown, and Dark brown; root colors, Symbols; the same letter means no significant difference within each tissue ( $p<0.05$, Bonferroni corrected Mann-Whitney pairwise comparisons),

*: Not observed.

\subsection{Comparison between Different Treatments}

The presence of both primary and secondary aerenchyma were confirmed irrespective of the medium used (Figure 1) and the color of the roots was found to correspond with the respective aerenchyma types (Figure 2). When flooding treatment was applied for six months, the proportion of the periderm in the dark brown part of the roots was not significantly different between the roots grown in the hydroponic and agar medium, but the cortex was significantly smaller in the agar medium (Figure 4).

\section{Discussion}

\subsection{Development and Spatial Patterns of Primary Aerenchyma in Cortex}

The order of occurrence of aerenchyma types in S. kunstleri was similar to that in soybean roots exposed to flooding [41]. Schizogenous and lysigenous aerenchyma appeared first in the cortex, and then secondary aerenchyma developed in the periderm.

In this study, the section of the adventitious roots in which the color changed from white to brown almost coincided with the section in which lysigenous aerenchyma started growing (Figure 1). Investigators usually use a combination of indicators when assessing the aging of roots, such as color changes, the loss of cortex, and the disappearance of fine roots [49]. Thus, because the advance of cell degradation in the cortex differs depending on the distance from the root tip (Figure 4), the cortical intercellular space varied depending on the section of root (Figure 1). The difference of development in cortical intercellular space along the roots would enable longitudinal diffusion of $\mathrm{O}_{2}$ from the shoots to the root tips.

Considering the observed cortical collapse near the root base, the independent development of lysigenous aerenchyma in roots cannot be seen as an optimal root form for hypoxic conditions [50]. The development of lysigenous aerenchyma is caused by cell death and degradation [13], but continued hypoxic conditions lead to cortical collapse that in turn leads to a decrease in the function of primary aerenchyma. Additionally, since the cortex is destroyed by secondary thickening, in some species cortical aerenchyma formation may be less important for survival under conditions of low $\mathrm{O}_{2}[24,50,51]$. 
Thus, in S. kunstleri, tissues that replace the function of primary aerenchyma as an internal $\mathrm{O}_{2}$ pathway can be considered as secondary aerenchyma.

\subsection{Development and Spatial Pattern of Secondary Aerenchyma in Periderm}

Secondary aerenchyma in soybean roots was seen to arise from cell divisions in the pericycle, and the entire secondary aerenchyma was found to consist only of cells resulting from that process [41]. Although the secondary aerenchyma of S. kunstleri also developed by cell division, in contrast to soybean, layers of phellem cells were observed, forming several layers in S. kunstleri (Figures 1 and 3). The repeated structure formed by the layers of phellem cells and the division of elongated cells between the layers of phellem cells seem to be a distinctive process in S. kunstleri for the formation of secondary aerenchyma. The secondary aerenchyma is part of the periderm, and occupies a large portion in the vicinity of the root base (Figures 1-3). Therefore, it seemed that the development of secondary aerenchyma was related with that of periderm.

The longitudinal distribution of periderm and secondary aerenchyma in a single adventitious root indicates that the development of periderm was an indicator of secondary aerenchyma development (Figures 1 and 3). As a result of observing the development of periderm, secondary aerenchyma seemed to be most developed in the dark brown sections of the roots (Figure 4). In addition, radially elongated cells positioned between the layers of phellem cells also appeared in multiple layers as a result of cell division, and intercellular space was observed (Figures 1 and 3).

\subsection{Function as Oxygen Transportation Pathway in Primary and Secondary Aerenchyma}

As the secondary growth of the roots progresses, cortex including primary aerenchyma collapses and peels off (Figure 1). Unless the collapse occurs, the primary aerenchyma is presumed to function as a pathway for oxygen [40]. As such a loss was not observed where the roots were white or light brown (Figure 1), the primary aerenchyma was considered to be functional in these parts of the root.

In order to function as a pathway for oxygen transport, it is important that there are enough spaces for secondary aerenchyma between layers of phellem cells [40]. In this study, only one layer of phellem cells was confirmed where the light brown roots were near the white parts or in the white parts themselves (Figures 1 and 2). This means that a pathway for oxygen was absent or low in these regions. On the other hand, in the light brown root, slightly away from the white parts, the layers of phellem cells were observed as two or more layers, with thick periderm (Figure 2), possibly functioning as a pathway for oxygen transport.

The primary aerenchyma was also predicted to be functional in this root region. Therefore, oxygen diffusion might occur through the primary and secondary aerenchyma types in this root region. Moreover, secondary aerenchyma also developed from the light brown region toward the root base (Figures 1 and 2), suggesting possible oxygen transport between the primary and secondary aerenchymas in this part of the root.

\subsection{Comparison among the Different Treatments}

Comparing the results of flooding treatment was applied for six months, proportion of the cortex in dark brown part of roots was significantly smaller in the agar medium than in the hydroponic medium (Figure 4). This result implies that the lower oxygen concentration induces cell degradation and cell death in the cortex [18]. Based on Figure 2, the thickness of periderm and number of layers of phellem cells were most developed in dark brown parts near the root base. Especially, the dark brown part of roots that grown for six months on agar media was the most developed. The development of secondary aerenchyma in the dark brown parts near the root base, where cortical cells degradation and secondary thickening were performed, was possibly believed to enhance adaptation to the hypoxic conditions. 


\section{Conclusions}

In S. kunstleri, which is a known flood-tolerant species, both primary and secondary aerenchyma were observed in adventitious roots grown in hypoxic conditions. In order to transport atmospheric oxygen to the root tip, the primary and secondary aerenchyma must be connected to one another, because primary aerenchyma is developed along the entire length of the roots, whereas secondary aerenchyma is not. Oxygen transportation occurs between primary and secondary aerenchyma from the point where two or more layers of phellem cells are formed, and the outermost layer of phellem cells is directly connected to the cortical intercellular space, allowing oxygen transfer between the two tissues to occur. That is, secondary aerenchyma in roots grown under hypoxic conditions can complement the oxygen transport function of primary aerenchyma. This study would provide the basis for understanding the morphological and anatomical adaptive mechanism to flooding condition of the tolerant woody plant species, which is expected to contribute to selection of woody tree species as planting stocks for afforestation of degraded peatlands.

Author Contributions: H.-D.S. and M.M. conceived and designed the experiments; H.-D.S. performed the experiments and analyzed the data; H.-D.S. and H.K. wrote the manuscript; T.T. supervised the research.

Funding: This study was financially supported in part by a Grant-in-Aid for Scientific Research to M.M. (\#22580158) from the Japan Society for the Promotion of Science.

Acknowledgments: The authors thank Takashi Yamanoshita, ANESC University of Tokyo, for providing plant materials and his instructive advices. We also thank Shoji Hashimoto for his helpful advice and revision of the manuscript.

Conflicts of Interest: The authors declare no conflict of interest.

\section{References}

1. Boyer, J.S. Plant productivity and environment. Science 1982, 218, 443-448. [CrossRef]

2. Abiko, T.; Kotula, L.; Shiono, K.; Malik, A.I.; Colmer, T.D.; Nakazono, M. Enhanced formation of aerenchyma and induction of a barrier to radial oxygen loss in adventitious roots of Zea nicaraguensis contribute to its waterlogging tolerance as compared with maize (Zea mays ssp. mays). Plant Cell Environ. 2012, 35, 1618-1630. [CrossRef] [PubMed]

3. Dawood, T.; Rieu, I.; Wolters-Arts, M.; Derksen, E.B.; Mariani, C.; Visser, E.J.W. Rapid flooding-induced adventitious root development from preformed primordia in Solanum dulcamara. AoB Plants 2014, 6. [CrossRef] [PubMed]

4. Grable, A.R. Soil aeration and plant growth. In Advances in Agronomy; Normane, A.G., Ed.; Academic Press: San Diego, CA, USA, 1966; Volume 18, pp. 57-106.

5. Yamauchi, T.; Watanabe, K.; Fukazawa, A.; Mori, H.; Abe, F.; Kawaguchi, K.; Oyanagi, A.; Nakazono, M. Ethylene and reactive oxygen species are involved in root aerenchyma formation and adaptation of wheat seedlings to oxygen-deficient conditions. J. Exp. Bot. 2013, 65, 261-271. [CrossRef] [PubMed]

6. Koevoets, I.T.; Venema, J.H.; Elzenga, J.T.M.; Testerink, C. Roots withstanding their environment: Exploiting root system architecture responses to abiotic stress to improve crop tolerance. Front. Plant Sci. 2016, 7, 1335. [CrossRef]

7. Armstrong, W. Aeration in higher plants. In Advances in Botanical Research; Woolhouse, H.W., Ed.; Academic Press: San Diego, CA, USA, 1980; Volume 7, pp. 225-332.

8. Dacey, J.W.H. Internal winds in water lilies: An adaptation for life in anaerobic sediments. Science 1980, 210, 1017-1019. [CrossRef]

9. Drew, M.C.; Saglio, P.H.; Pradet, A. Larger adenylate energy charge and ATP/ADP ratios in aerenchymatous roots of Zea mays in anaerobic media as a consequence of improved internal oxygen-transport. Planta 1985, 165, 51-58. [CrossRef] [PubMed]

10. Drew, M.C. Oxygen deficiency and root metabolism: Injury and acclimation under hypoxia and anoxia. Annu. Rev. Plant Biol. 1997, 48, 223-250. [CrossRef]

11. Shimamura, S.; Yoshida, S.; Mochizuki, T. Cortical aerenchyma formation in hypocotyl and adventitious roots of Luffa cylindrica subjected to soil flooding. Ann. Bot. 2007, 100, 1431-1439. [CrossRef] 
12. Takahashi, H.; Yamauchi, T.; Colmer, T.D.; Nakazono, M. Aerenchyma formation in plants. In Low-Oxygen Stress in Plants: Oxygen Sensing and Adaptive Response to Hypoxia; van Dongen, J.T., Licausi, F., Eds.; Plant Cell Monographs: Vienna, Austria, 2014; pp. 247-265.

13. Evans, D.E. Aerenchyma formation. New phytol. 2004, 161, 35-49. [CrossRef]

14. Folzer, H.; Dat, J.F.; Capelli, N.; Rieffel, D.; Badot, P.M. Response of sessile oak seedlings (Quercus petraea) to flooding: An integrated study. Tree Physiol. 2006, 26, 759-766. [CrossRef] [PubMed]

15. Drew, M.C.; He, C.J.; Morgan, P.W. Programmed cell death and aerenchyma formation in roots. Trends Plant Sci. 2000, 5, 123-127. [CrossRef]

16. Drew, M.C.; Jackson, M.B.; Giffard, S. Ethylene-promoted adventitious rooting and development of cortical air spaces (aerenchyma) in roots may be adaptive responses to flooding in Zea mays L. Planta 1979, 147, 83-88. [CrossRef]

17. Drew, M.C.; Jackson, M.B.; Giffard, S.C.; Campbell, R. Inhibition by silver ions of gas space (aerenchyma) formation in adventitious roots of Zea mays L. subjected to exogenous ethylene or to oxygen deficiency. Planta 1981, 153, 217-224. [CrossRef] [PubMed]

18. Gunawardena, A.H.; Pearce, D.M.; Jackson, M.B.; Hawes, C.R.; Evans, D.E. Characterisation of programmed cell death during aerenchyma formation induced by ethylene or hypoxia in roots of maize (Zea mays L.). Planta 2001, 212, 205-214. [CrossRef] [PubMed]

19. Justin, S.H.F.W.; Armstrong, W. Evidence for the involvement of ethene in aerenchyma formation in adventitious roots of rice (Oryza sativa L.). New Phytol. 1991, 118, 49-62. [CrossRef]

20. Arikado, H.; Adachi, Y. Anatomical and ecological responses of barley and some forage crops to the flooding treatment. Bull. Fac. Agric. Mie. Univ. 1955, 11, 1-29.

21. Huang, B.; Johnson, J.W.; Box, J.E.; NeSmith, D.S. Root characteristics and hormone activity of wheat in response to hypoxia and ethylene. Crop Sci. 1997, 37, 812-818. [CrossRef]

22. Trought, M.C.T.; Drew, M.C. Development of waterlogging damage in wheat seedlings (Triticum aestivum L.). 1. Shoot and root growth in relation to changes in the concentrations of dissolved gases and solutes in the soil solution. Plant Soil 1980, 54, 77-94. [CrossRef]

23. Laan, P.; Berrevoets, M.J.; Lythe, S.; Armstrong, W.; Blom, C.W.P.M. Root morphology and aerenchyma formation as indicators of the flood-tolerance of Rumex species. J. Ecol. 1989, 77, 693-703. [CrossRef]

24. Jackson, M.B.; Armstrong, W. Formation of aerenchyma and the processes of plant ventilation in relation to soil flooding and submergence. Plant Biology 1999, 1, 274-287. [CrossRef]

25. Colmer, T.D.; Peeters, A.J.M.; Wagemaker, C.A.M.; Vriezen, W.H.; Ammerlaan, A.; Voesenek, L.A.C.J. Expression of a-expansin genes during root acclimations to $\mathrm{O}_{2}$ deficiency in Rumex palustris. Plant Mol. Biol. 2004, 56, 423-437. [CrossRef]

26. Schussler, E.E.; Longstreth, D.J. Aerenchyma develops by cell lysis in roots and cell separation in leaf petioles in Sagittaria lancifolia (Alismataceae). Am. J. Bot. 1996, 83, 1266-1273. [CrossRef]

27. Shimamura, S.; Yamamoto, R.; Nakamura, T.; Shimada, S.; Komatsu, S. Stem hypertrophic lenticels and secondary aerenchyma enable oxygen transport to roots of soybean in flooded soil. Ann. Bot. 2010, 106, 277-284. [CrossRef] [PubMed]

28. Shimamura, S.; Mochizuki, T.; Nada, Y.; Fukuyama, M. Formation and function of secondary aerenchyma in hypocotyl, roots and nodules of soybean (Glycine max) under flooded conditions. Plant Soil 2003, 251, 351-359. [CrossRef]

29. Stevens, K.J.; Peterson, R.L.; Reader, R.J. The aerenchymatous phellem of Lythrum salicaria (L.): A pathway for gas transport and its role in flood tolerance. Ann. Bot. 2002, 89, 621-625. [CrossRef] [PubMed]

30. Lempe, J.; Stevens, K.J.; Peterson, R.L. Shoot responses of six Lythraceae Species to flooding. Plant Biology 2001, 3, 186-193. [CrossRef]

31. Stevens, K.J.; Peterson, R.L.; Stephenson, G.R. Morphological and anatomical responses of Lythrum salicaria L. (Purple Loosestrife) to an imposed water gradient. Int. J. Plant Sci. 1997, 158, 172-183.

32. Scott, D.H.; Wager, H. On the floating-roots of Sesbania aculeata, Pers: With plate xvii. Ann. Bot. 1888, 1, 307-314. [CrossRef]

33. Shiba, H.; Daimon, H. Histological observation of secondary aerenchyma formed immediately after flooding in Sesbania cannabina and S. rostrata. Plant Soil 2003, 255, 209-215. [CrossRef]

34. Saraswati, R.; Matoh, T.; Sekiya, J. Nitrogen fixation of Sesbania rostrata: Contribution of stem nodules to nitrogen acquisition. Soil Sci. Plant Nutr. 1992, 38, 775-780. [CrossRef] 
35. Metcalfe, C.R. The "aerenchyma" of Sesbania and Neptunia. Bull. Misc. Inf. (Royal Bot. Gard., Kew) 1931, 1931, 151-154. [CrossRef]

36. Walker, B.A.; Pate, J.S.; Kuo, J. Nitrogen fixation by nodulated roots of Viminaria juncea (Schrad. and Wendl.) Hoffmans (Fabaceae) when submerged in water. Aust. J. Plant Physiol. 1983, 10, 409-421. [CrossRef]

37. Yamauchi, T.; Shimamura, S.; Nakazono, M.; Mochizuki, T. Aerenchyma formation in crop species: A review. Field Crop. Res. 2013, 152, 8-16. [CrossRef]

38. Rich, S.M.; Ludwig, M.; Pederson, O.; Colmer, T.D. Aquatic adventitious roots of the wetland plant Meionectes brownie can photosynthesize: Implications for root function during flooding. New Phytol. 2011, 190, 311-319. [CrossRef] [PubMed]

39. Moog, P.R. Flooding tolerance of Carex species. I. Root structure. Planta 1998, 207, 189-198. [CrossRef]

40. Somavilla, N.S.; Graciano-Ribeiro, D. Ontogeny and characterization of aerenchymatous tissues of Melastomataceae in the flooded and well-drained soils of a Neotropical savanna. Flora 2012, 207, 212-222. [CrossRef]

41. Thomas, A.L.; Guerreiro, S.M.C.; Sodek, L. Aerenchyma formation and recovery from hypoxia of the flooded root system of nodulated soybean. Ann. Bot. 2005, 96, 1191-1198. [CrossRef]

42. Shimamura, S.; Yoshioka, T.; Yamamoto, R.; Hiraga, S.; Nakamura, T.; Shimada, S.; Komatsu, S. Role of abscisic acid in flood-induced secondary aerenchyma formation in soybean (Glycine max) hypocotyls. Plant Prod. Sci. 2014, 17, 131-137. [CrossRef]

43. Shimamura, S.; Nishimura, T.; Koshiba, T.; Yamamoto, R.; Hiraga, S.; Nakamura, T.; Komatsu, S. Effects of anti-auxins on secondary aerenchyma formation in flooded soybean hypocotyls. Plant Prod. Sci. 2016, 19, 154-160. [CrossRef]

44. Tanaka, K.; Masumori, M.; Yamanoshita, T.; Tange, T. Morphological and anatomical changes of Melaleuca cajuputi under submergence. Trees 2011, 25, 695-704. [CrossRef]

45. Brundrett, M.C.; Kendrick, B.; Peterson, C.A. Efficient lipid staining in plant material with sudan red 7b or fluoral yellow 088 in polyethylene glycol-glycerol. Biotech. Histochem. 1991, 66, 111-116. [CrossRef] [PubMed]

46. Lux, A.; Morita, S.; Abe, J.; Ito, K. An improved method for clearing and staining free-hand sections and whole-mount samples. Ann. Bot. 2005, 96, 989-996. [CrossRef] [PubMed]

47. Visser, E.J.W.; Bogemann, G.M. Measurement of porosity in very small samples of plant tissue. Plant Soil 2003, 253, 81-90. [CrossRef]

48. Burton, A.L.; Williams, M.; Lynch, J.P.; Brown, K.M. Rootscan: Software for high-throughput analysis of root anatomical traits. Plant Soil 2012, 357, 189-203. [CrossRef]

49. Eissenstat, D.M.; Yanai, R.D. The ecology of root lifespan. In Advances in Ecological Research; Begon, M., Fitter, A.H., Eds.; Academic Press: San Diego, CA, USA, 1997; Volume 27, pp. 1-60.

50. De Simone, O.; Haase, K.; Muller, E.; Junk, W.J.; Gonsior, G.; Schmidt, W. Impact of root morphology on metabolism and oxygen distribution in roots and rhizosphere from two central amazon floodplain tree species. Funct. Plant Biol. 2002, 29, 1025-1035. [CrossRef]

51. Justin, S.H.F.W.; Armstrong, W. The anatomical characteristics of roots and plant response to soil flooding. New Phytol. 1987, 106, 465-495. [CrossRef]

(C) 2019 by the authors. Licensee MDPI, Basel, Switzerland. This article is an open access article distributed under the terms and conditions of the Creative Commons Attribution (CC BY) license (http:/ / creativecommons.org/licenses/by/4.0/). 